\title{
Impact of climate change and man-made irrigation systems on the transmission risk, long-term trend and seasonality of human and animal fascioliasis in Pakistan
}

\author{
Kiran Afshan ${ }^{1,2}$, Cesar A. Fortes-Lima ${ }^{1}$, Patricio Artigas ${ }^{1}$, M. Adela Valero ${ }^{1}$, Mazhar \\ Qayyum $^{2}$, Santiago Mas-Coma ${ }^{1}$ \\ ${ }^{1}$ Departamento de Parasitología, Facultad de Farmacia, Universidad de Valencia, Burjassot, Valencia, Spain; \\ ${ }^{2}$ Department of Zoology, Pir Mehr Ali Shah-Arid Agriculture University, Rawalpindi, Pakistan
}

\begin{abstract}
Large areas of the province of Punjab, Pakistan are endemic for fascioliasis, resulting in high economic losses due to livestock infection but also affecting humans directly. The prevalence in livestock varies pronouncedly in space and time $(1-70 \%)$. Climatic factors influencing fascioliasis presence and potential spread were analysed based on data from five meteorological stations during 1990-2010. Variables such as wet days (Mt), water-budget-based system (Wb-bs) indices and the normalized difference vegetation index (NDVI), were obtained and correlated with geographical distribution, seasonality patterns and the two-decade evolution of fascioliasis in livestock throughout the province. The combined approach by these three indices proved to furnish a useful tool to analyse the complex epidemiology that includes (i) sheep-goats and cattlebuffaloes presenting different immunological responses to fasciolids; (ii) overlap of Fasciola hepatica and F. gigantica; (iii) co-existence of highlands and lowlands in the area studied; and (iv) disease transmission following bi-seasonality with one peak related to natural rainfall and another peak related to man-made irrigation. Results suggest a human infection situation of concern and illustrate how climate and anthropogenic environment modifications influence both geographical distribution and seasonality of fascioliasis risks. Increased fascioliasis risk throughout the Punjab plain and its decrease in the northern highlands of the province became evident during the study period. The high risk in the lowlands is worrying given that Punjab province largely consists of low-altitude, highly irrigated plains. The importance of livestock in this province makes it essential to prioritise adequate control measures. An annual treatment scheme to control the disease is recommended to be applied throughout the whole province.
\end{abstract}

Keywords: fascioliasis, Fasciola hepatica, Fasciola gigantica, livestock, humans, climatic data, forecast indices, normalized difference vegetation index, climate change, Pakistan.

\section{Introduction}

Fascioliasis is caused by Fasciola hepatica in Europe, Africa, Asia, the Americas and Oceania, while it can also be due to F. gigantica in Africa and Asia; both parasites are transmitted by lymnaeid snails (Bargues and Mas-Coma, 2005). Well known in the veterinary field, this disease is also of public health impact with human case numbers and endemic areas increasing in five continents (Mas-Coma et al., 2009a). Human fascioliasis is goining importance with the current, improved understanding of its morbidity due to sustained infection (Valero et al., 2003, 2006, 2008; Girones et al., 2007). Due to the parasite/snail rela-

\footnotetext{
Corresponding author:

Santiago Mas-Coma

Departamento de Parasitología

Facultad de Farmacia, Universidad de Valencia

Av. Vicent Andres Estelles s/n, 46100 Burjassot, Valencia, Spain

Tel. +34 96 354-4298; Fax +34 96 354-4769

E-mail: S.Mas.Coma@uv.es
}

tionship, the disease is highly dependent on climatic and environmental characteristics (Ollerenshaw and Smith, 1969; Ollerenshaw, 1974), which explains the influence of climate change and anthropogenic modifications of the environment (e.g. construction of dams, irrigation canals and water reservoirs) observed in different areas (Mas-Coma et al., 2008, 2009b).

Reports indicate that human fascioliasis is emerging in southern Asia, a wide region pronouncedly influenced by climate change (Cruz et al., 2007). Pakistan has become key for this endeavour: (i) the first human fascioliasis cases have only recently been reported in the rural areas of the Lahore district, Punjab province (Qureshi et al., 2005b; Qureshi, 2008; Qureshi and Tanveer, 2009); (ii) it is centrally located inside this wide region; (iii) a climate change impact has already been detected in the country (Farooq and Kahn, 2004; Rasul et al., 2012); and (iv) there is a vast irrigation system that feeds more than 40 million acres of irrigated land. Thus, Punjab presents the highest ratio of irrigated to rain-fed land in the world, 4:1 (Nizamani et al., 1998). 
Table 1. Fascioliasis prevalence rates (\%) reported in humans and livestock in localities (districts) of Pakistan, including the fasciolid species found: Fasciola spp. (Fs), F. hepatica (Fh), F. gigantica (Fg); and diagnostic method used.

\begin{tabular}{|c|c|c|c|c|c|c|c|c|c|}
\hline Species & $\mathrm{D}^{1}$ & Host & $\mathrm{N}^{2}$ & Pos. $^{3}$ & Prev. $^{4}$ & Locality (district) & Alt. ${ }^{5}$ & Period & Reference \\
\hline Fs & $\mathrm{C}$ & Human & $7,200 *$ & 21 & 0.31 & Lahore & 216 & Apr 2003-Mar 2005 & Qureshi et al. (2005b) \\
\hline Fs & S & Human & 300 & 14 & 4.7 & Lahore & 216 & Apr 2003-Mar 2005 & Qureshi and Tanveer (2009) \\
\hline Fs & S & Buffalo & 50 & 4 & 8.0 & Sheikhupura & 209 & Apr 2003-Mar 2005 & Qureshi and Tanveer (2009) \\
\hline Fs & S & Buffalo & 50 & 5 & 10.0 & Gujranwala & 225 & Apr 2003-Mar 2005 & Qureshi and Tanveer (2009) \\
\hline Fs & $S$ & Buffalo & 50 & 7 & 14.0 & Kasur & 208 & Apr 2003-Mar 2005 & Qureshi and Tanveer (2009) \\
\hline Fs & S & Buffalo & 50 & 10 & 20.0 & Shahdara & 211 & Apr 2003-Mar 2005 & Qureshi and Tanveer (2009) \\
\hline Fs & S & Buffalo & 50 & 16 & 32.0 & Kamoke & 217 & Apr 2003-Mar 2005 & Qureshi and Tanveer (2009) \\
\hline Fs & S & Buffalo & 50 & 13 & 26.0 & Muridke & 216 & Apr 2003-Mar 2005 & Qureshi and Tanveer (2009) \\
\hline Fs & $\mathrm{C}$ & Cattle & 960 & 387 & 40.3 & Sargodha & 192 & Nov 2006-Oct 2007 & Khan et al. (2009) \\
\hline Fs & $\mathrm{C}$ & Cattle & 960 & 329 & 34.3 & Jhang & 157 & Nov 2006-Oct 2007 & Khan et al. (2009) \\
\hline Fs & $\mathrm{C}$ & Cattle & 960 & 200 & 20.8 & Muzaffargarh & 118 & Nov 2006-Oct 2007 & Khan et al. (2009) \\
\hline Fs & $\mathrm{C}$ & Cattle & 960 & 193 & 20.1 & Lodhran & 117 & Nov 2006-Oct 2007 & Khan et al. (2009) \\
\hline Fs & $\mathrm{C}$ & Cattle & 960 & 113 & 11.8 & Layyah & 148 & Nov 2006-Oct 2007 & Khan et al. (2009) \\
\hline Fs & $\mathrm{C}$ & Sheep & 90 & 4 & 4.4 & Islamabad & 575 & Aug 2004-May 2008 & Gadahi et al. (2009) \\
\hline Fs & $\mathrm{C}$ & Sheep & 90 & 4 & 4.4 & Rawalpindi & 503 & Aug 2004-May 2008 & Gadahi et al. (2009) \\
\hline Fs & $\mathrm{C}$ & Goat & 310 & 2 & 0.64 & Islamabad & 575 & Aug 2004-May 2008 & Gadahi et al. (2009) \\
\hline Fs & $\mathrm{C}$ & Goat & 310 & 2 & 0.64 & Rawalpindi & 503 & Aug 2004-May 2008 & Gadahi et al. (2009) \\
\hline Fs & $\mathrm{C}$ & Cattle & 1,140 & 281 & 24.7 & Toba Tek Singh & 160 & Jan 2008-Dec 2008 & Khan et al. (2010) \\
\hline Fs & $\mathrm{C}$ & Buffalo & 1,140 & 369 & 32.4 & Toba Tek Singh & 160 & Jan 2008-Dec 2008 & Khan et al. (2010) \\
\hline Fs & $\mathrm{C}$ & Sheep & 840 & 294 & 35.0 & Toba Tek Singh & 160 & Jan 2008-Dec 2008 & Khan et al. (2010) \\
\hline Fs & $\mathrm{C}$ & Goat & 660 & 219 & 33.2 & Toba Tek Singh & 160 & Jan 2008-Dec 2008 & Khan et al. (2010) \\
\hline Fs & $\mathrm{H}$ & Sheep & 261 & 52 & 23.8 & Quetta & 1,693 & Aug 2001-Mar 2002 & Ahmed et al. (2005) \\
\hline Fs & $\mathrm{H}$ & Goat & 43 & 12 & 27.9 & Quetta & 1,693 & Aug 2001-Mar 2002 & Ahmed et al. (2005) \\
\hline $\mathrm{Fh}$ & $\mathrm{C}$ & Cattle & 674 & 476 & 70.6 & Farooqia & 132 & Not specified & Iqbal et al. (2007) \\
\hline $\mathrm{Fh}$ & $\mathrm{C}$ & Cattle & 135 & 22 & 16.3 & Kot Addu & 131 & Not specified & Iqbal et al. (2007) \\
\hline $\mathrm{Fh}$ & $\mathrm{C}$ & Cattle & 165 & 53 & 32.1 & Dunya Pur & 121 & Not specified & Iqbal et al. (2007) \\
\hline $\mathrm{Fh}$ & $\mathrm{C}$ & Cattle & 56 & 12 & 21.4 & Layyah & 148 & Not specified & Iqbal et al. (2007) \\
\hline $\mathrm{Fh}$ & $\mathrm{C}$ & Cattle & 65 & 26 & 40.0 & Mor Mandi & 162 & Not specified & Iqbal et al. (2007) \\
\hline $\mathrm{Fh}$ & $\mathrm{C}$ & Cattle & 93 & 43 & 46.2 & Shorkot & 149 & Not specified & Iqbal et al. (2007) \\
\hline $\mathrm{Fh}$ & $\mathrm{C}$ & Cattle & 117 & 29 & 24.8 & Jalalpur & 159 & Not specified & Iqbal et al. (2007) \\
\hline $\mathrm{Fh}$ & $\mathrm{C}$ & Cattle & 1,140 & 52 & 4.6 & Toba Tek Singh & 160 & Jan 2008-Dec 2008 & Khan et al. (2010) \\
\hline $\mathrm{Fh}$ & $\mathrm{C}$ & Buffalo & 1,140 & 77 & 6.8 & Toba Tek Singh & 160 & Jan 2008-Dec 2008 & Khan et al. (2010) \\
\hline $\mathrm{Fh}$ & $\mathrm{C}$ & Sheep & 840 & 59 & 7.0 & Toba Tek Singh & 160 & Jan 2008-Dec 2008 & Khan et al. (2010) \\
\hline $\mathrm{Fh}$ & $\mathrm{C}$ & Goat & 660 & 50 & 7.6 & Toba Tek Singh & 160 & Jan 2008-Dec 2008 & Khan et al. (2010) \\
\hline $\mathrm{Fh}$ & $\mathrm{H}$ & Cattle & 288 & 44 & 15.2 & Quetta & 1,693 & May 2008-Dec.2008 & Kakar et al. (2011) \\
\hline $\mathrm{Fh}$ & $\mathrm{H}$ & Buffalo & 201 & 29 & 14.4 & Quetta & 1,693 & May 2008-Dec.2008 & Kakar et al. (2011) \\
\hline $\mathrm{Fg}$ & $\mathrm{C}$ & Cattle & 1,140 & 229 & 20.1 & Toba Tek Singh & 160 & Jan 2008-Dec 2008 & Khan et al. (2010) \\
\hline $\mathrm{Fg}$ & $\mathrm{C}$ & Buffalo & 1,140 & 292 & 25.6 & Toba Tek Singh & 160 & Jan 2008-Dec 2008 & Khan et al. (2010) \\
\hline $\mathrm{Fg}$ & $\mathrm{C}$ & Sheep & 840 & 235 & 28.0 & Toba Tek Singh & 160 & Jan 2008-Dec 2008 & Khan et al. (2010) \\
\hline $\mathrm{Fg}$ & $\mathrm{C}$ & Goat & 660 & 169 & 25.6 & Toba Tek Singh & 160 & Jan 2008-Dec 2008 & Khan et al. (2010) \\
\hline $\mathrm{Fg}$ & $\mathrm{H}$ & Cattle & 288 & 10 & 3.4 & Quetta & 1,693 & May 2008-Dec 2008 & Kakar et al. (2011) \\
\hline $\mathrm{Fg}$ & $\mathrm{H}$ & Buffalo & 201 & 8 & 3.9 & Quetta & 1,693 & May 2008-Dec 2008 & Kakar et al. (2011) \\
\hline $\mathrm{Fg}$ & $\mathrm{C}$ & Goats & 600 & 173 & 28.8 & Kamoke & 219 & Jan 2004-Dec1994 & Maqbool et al. (2000) \\
\hline $\mathrm{Fg}$ & $\mathrm{H}$ & Goats & 600 & 220 & 36.6 & Kamoke & 219 & Jan 2004-Dec1994 & Maqbool et al. (2000) \\
\hline Fs & $\mathrm{C}$ & Sheep & 90 & 4 & 4.4 & Rawalpindi/Islamabad & $503-575$ & Aug 2004-May 2008 & Gadahi et al. (2009) \\
\hline Fs & $\mathrm{C}$ & Goats & 310 & 19 & 0.6 & Rawalpindi/Islamabad & $503-575$ & Aug 2004-May 2008 & Gadahi et al. (2009) \\
\hline $\mathrm{Fh}$ & $\mathrm{C}$ & Sheep & 523 & 112 & 21.4 & Southern Punjab ${ }^{5}$ & $125-140$ & Not specified & Lashari and Tasawar (2011) \\
\hline $\mathrm{Fg}$ & $\mathrm{H}$ & Buffalo & 330 & 45 & 14.8 & Hyderabad & 30 & Not specified & Shaikh et al. (2004) \\
\hline
\end{tabular}

${ }^{1}$ Diagnostic approach: coprology $(\mathrm{C})$, serology $(\mathrm{S})$ and histopathology $(\mathrm{H}) ;{ }^{2}$ Total number of individuals analysed ("refers to samples studied); ${ }^{3}$ Number of infected host individuals; ${ }^{4}$ Prevelence; ${ }^{5}$ Altitude (in m); ${ }^{6}$ Dera Ghazi Khan, Multan and Khaneval. 
Punjab is the largest and most densely populated part of Pakistan, most of its inhabitants depending on agriculture and livestock, while fascioliasis has been reported to be widespread in buffaloes, cattle, sheep and goats since long ago (references in Table 1). Prevalences appear to vary pronouncedly, from less than $1 \%$ in northern Islamabad and Rawalpindi hills area (Gadahi et al., 2009) to $70.6 \%$ in Farooqia on the Punjab plain where stagnant water stays long as it is not easily absorbed into the soil (Iqbal et al., 2007). Prevalence rates are lower in the southern part of the province (cattle $9 \%$, buffaloes $4 \%$, sheep $2 \%$, goats $3 \%$ ) (Raza et al., 2007). Additionally, both mono-seasonal and bi-seasonal transmission patterns of fascioliasis have been detected (Maqbool et al., 2002; Khan et al., 2009, 2010), confirming the heterogeneous picture and underlining why the economic losses in Punjab province are particularly high (Chaudhry and Niaz, 1984; Chaudry et al., 1984; Khan et al., 2009).

In Pakistan, fascioliasis is also present in other provinces: $4 \%$ prevalence in buffaloes from Hyderabad in Sindh province (Bhutto et al., 2002); in sheep $(7.7 \%)$, goats $(7.0 \%)$, cows $(12.4-16.2 \%)$ and buffaloes $(11.5-13.5 \%)$ in Quetta $(1,693 \mathrm{~m})$, Balochistan province (Nawaz and Nawaz, 1987a,b; Ahmed et al., 2005; Kakar and Kakarsulemankhel, 2008; Kakar et al., 2011); in buffaloes (5.9\%) of the northern Khadagzai area, Dir district, Hindu Kush Range (Azam et al., 2002) (Fig. 1a). Altitudes vary from $30 \mathrm{~m}$ above mean sea level (MSL) in Hyderabad to $1,693 \mathrm{~m}$ in Quetta.

There is an overlap of the two fasciolid species (Chaudhry and Niaz, 1984; Masud and Majid, 1984; Maqbool et al., 2000, 2002; Khan et al., 2009, 2010). Mixed infections of F. hepatica and F. giganti$c a$ occur on the boundaries of highland areas, presumably as a result of the movement of stock between high and low ground or through overlapping of the territories of the snail intermediate host. Thus, in upland districts as Dir, Swat and Chitral, F. gigantica is replaced by $F$. hepatica (Kendall, 1954). In the upland of Quetta, F. gigantica mostly exceeded F. bepatica due to the fact that animals are brought from the lowlands because of their lower cost (Ahmed et al., 2005). Interestingly, only F. hepatica was reported in sheep and goats in Asghara valley of Ziarat, Balochistan (Razzaq et al., 2002), while mixed infections were reported in sheep from the Faisalabad lowlands (Hayat et al., 1986; Iqbal et al., 1986). In Punjab province, results indicate that $F$. gigantica is more widespread than F. hepatica (Khan et al., 2009). Lastly, the presence of F. hepatica/F. gigantica intermediate forms has been confirmed in Punjab by fasciolid adult and egg phenotyping (Afshan et al., 2013) by computer image analysis system (CIAS) methodology (Valero et al., 2005).

This study aims at analysing the climatic factors influencing fascioliasis in Punjab, with emphasis on climate change and man-made environmental modifications, based on forecast climatic indices and remote sensing data. The 1990-2010 period is analysed to assess a potential recent increase of fascioliasis risk which may explain human infection reported in the last decade. This study represents an effort to obtain the baseline on which to establish appropriate control measures for Punjab province.

\section{Materials and methods}

\section{Study area}

The study zone comprises the province of Punjab, with emphasis on the districts of Rawalpindi, Jhelum, Lahore, Sargodha and Faisalabad (Fig. 1a). Local grazing is practised in cultivated lands or adjoining forests throughout the year. Nomadic and semi-nomadic grazing to and back from alpine pastures in Himalaya foothills have a long history. The Punjab province consists of a large plain with some hilly areas in the North-West and extreme SouthWest. There is the Potwar Plateau adjacent to the mountains and a desert belt in the south-eastern part known as Cholistan. The Indus River and its tributaries, originating from the Himalayas and flowing from north-west to south-west, feed the plain (Fig. 1b). After the monsoon rains in the summer, the flow of water increases, sometimes resulting in flooding. A great amount of this water is used for irrigation including dams, barrages and a canal network of about $60,000 \mathrm{~km}$.

\section{Climatic data}

Monthly climatic data from a 21-year period (1990-2010) were obtained from five meteorological stations, selected to provide representative information for the three rainfall regions of the Punjab province (Hussain and Lee, 2009) (Table 2, Fig. 1). Meteorological variables obtained from each station are given in Table 2. Seasonality was assessed by representing mean monthly data of the aforementioned factors in yearly graphs and climate diagrams. 

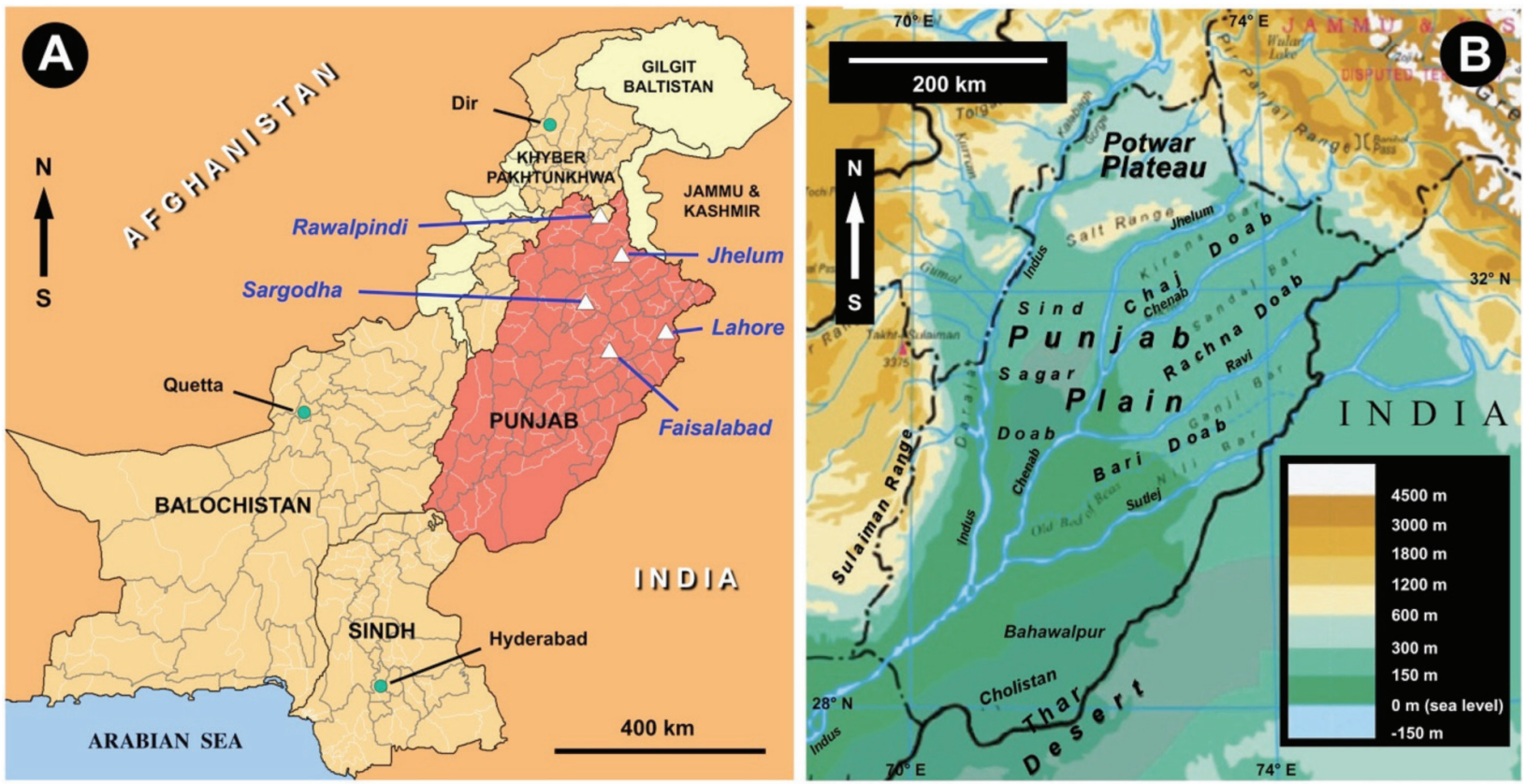

Fig. 1. (a) Map of Pakistan showing the provinces, the five meteorological stations (white triangles) and the localities-districts (green circles) of Hyderabal, Quetta and Dir where fascioliasis in livestock has also been detected. (b) Map of Punjab province showing the main orographic characteristics (surface, relief and altitudes) and the Indus River system with tracts of land between tributaries (doabs).

Table 2. Mean values $( \pm \mathrm{SD})$ and extreme values [ranges] of the climatic factors furnished by the five meteorological stations in Punjab province, Pakistan for the 1990-2010 period.

\begin{tabular}{|c|c|c|c|c|c|}
\hline & \multicolumn{5}{|c|}{ Meteorological stations } \\
\hline & Rawalpindi & Jhelum & Lahore & Sargodha & Faisalabad \\
\hline $\begin{array}{l}\text { Geographical } \\
\text { coordinates }\end{array}$ & $\begin{array}{l}33^{\circ} 36^{\prime} 20^{\prime \prime} \mathrm{N} \\
73^{\circ} 02^{\prime} 37^{\prime \prime} \mathrm{E}\end{array}$ & $\begin{array}{l}32^{\circ} 56^{\prime} 00^{\prime \prime} \mathrm{N} \\
73^{\circ} 43^{\prime} 14^{\prime \prime} \mathrm{E}\end{array}$ & $\begin{array}{l}31^{\circ} 32^{\prime} 42^{\prime \prime} \mathrm{N} \\
74^{\circ} 20^{\prime} 27^{\prime \prime} \mathrm{E}\end{array}$ & $\begin{array}{l}32^{\circ} 04^{\prime} 44^{\prime \prime} \mathrm{N} \\
72^{\circ} 40^{\prime} 18^{\prime \prime} \mathrm{E}\end{array}$ & $\begin{array}{l}31^{\circ} 24^{\prime} 32^{\prime \prime} \mathrm{N} \\
73^{\circ} 05^{\prime} 00^{\prime \prime} \mathrm{E}\end{array}$ \\
\hline \multirow[t]{2}{*}{ Altitude (m) } & 502 & 228 & 217 & 190 & 186 \\
\hline & \multicolumn{5}{|c|}{ Climatic factors } \\
\hline $\operatorname{MET}^{1}\left({ }^{\circ} \mathrm{C}\right)$ & $\begin{array}{c}21.69 \pm 7.23 \\
{[9.00-32.50]}\end{array}$ & $\begin{array}{c}23.94 \pm 7.16 \\
{[10.50-39.50]}\end{array}$ & $\begin{array}{c}24.95 \pm 6.92 \\
{[10.90-35.10]}\end{array}$ & $\begin{array}{l}24.65 \pm 7.63 \\
{[9.50-35.50]}\end{array}$ & $\begin{array}{c}24.33 \pm 7.57 \\
{[10.10-35.10]}\end{array}$ \\
\hline $\operatorname{MmT}^{2}\left({ }^{\circ} \mathrm{C}\right)$ & $\begin{array}{c}14.69 \pm 7.83 \\
{[1.00-28.30]}\end{array}$ & $\begin{array}{c}17.16 \pm 7.67 \\
{[3.60-27.30]}\end{array}$ & $\begin{array}{c}19.34 \pm 7.32 \\
{[5.50-29.20]}\end{array}$ & $\begin{array}{c}17.82 \pm 8.21 \\
{[1.30-28.80]}\end{array}$ & $\begin{array}{c}17.58 \pm 8.11 \\
{[2.30-29.30]}\end{array}$ \\
\hline $\operatorname{MMT}^{3}\left({ }^{\circ} \mathrm{C}\right)$ & $\begin{array}{c}28.67 \pm 6.89 \\
{[15.20-40.50]}\end{array}$ & $\begin{array}{c}30.55 \pm 6.84 \\
{[16.10-42.90]}\end{array}$ & $\begin{array}{c}30.60 \pm 6.76 \\
{[15.10-41.70]}\end{array}$ & $\begin{array}{c}31.40 \pm 7.25 \\
{[14.90-43.40]}\end{array}$ & $\begin{array}{c}31.05 \pm 7.24 \\
{[15.90-41.90]}\end{array}$ \\
\hline $\operatorname{RAIN}(\mathrm{mm})$ & $\begin{array}{c}103.21 \pm 128.28 \\
{[0.00-801.40]}\end{array}$ & $\begin{array}{c}74.52 \pm 99.84 \\
{[0.00-648.10]}\end{array}$ & $\begin{array}{c}55.95 \pm 83.80 \\
{[0.00-640.00]}\end{array}$ & $\begin{array}{c}37.65 \pm 49.99 \\
{[0.00-283.70]}\end{array}$ & $\begin{array}{c}33.02 \pm 47.15 \\
{[0.00-300.30]}\end{array}$ \\
\hline $\mathrm{RH}^{4}(\%)$ & $\begin{array}{c}60.03 \pm 12.74 \\
{[29.00-81.00]}\end{array}$ & $\begin{array}{c}59.56 \pm 13.53 \\
{[25.00-84.00]}\end{array}$ & $\begin{array}{c}57.61 \pm 13.39 \\
{[26.00-83.00]}\end{array}$ & $\begin{array}{c}62.91 \pm 12.28 \\
{[31.00-90.00]}\end{array}$ & $\begin{array}{c}59.83 \pm 11.93 \\
{[32.00-90.00]}\end{array}$ \\
\hline $\operatorname{MEv}^{5}(\mathrm{~mm})$ & $\begin{array}{c}3.79 \pm 1.94 \\
{[0.80-8.60]}\end{array}$ & $\begin{array}{c}4.16 \pm 1.84 \\
{[0.80-8.50]}\end{array}$ & $\begin{array}{c}4.34 \pm 1.82 \\
{[1.10-8.30]}\end{array}$ & $\begin{array}{c}4.14 \pm 1.96 \\
{[0.90-8.50]}\end{array}$ & $\begin{array}{c}4.23 \pm 2.02 \\
{[1.10-9.10]}\end{array}$ \\
\hline $\mathrm{MSH}^{6}$ (hours) & $\begin{array}{c}241.38 \pm 51.56 \\
{[99.50-368.20]}\end{array}$ & $\begin{array}{c}232.03 \pm 46.30 \\
{[101.30-334.60]}\end{array}$ & $\begin{array}{c}240.16 \pm 42.83 \\
{[85.90-330.10]}\end{array}$ & $\begin{array}{c}229.68 \pm 45.23 \\
{[98.70-328.00]}\end{array}$ & $\begin{array}{c}238.93 \pm 46.60 \\
{[73.00-364.40]}\end{array}$ \\
\hline $\operatorname{MSR}^{7}\left(\mathrm{~W} / \mathrm{m}^{2}\right)$ & $\begin{array}{c}16.87 \pm 5.11 \\
{[6.68-27.27]}\end{array}$ & $\begin{array}{c}16.15 \pm 4.77 \\
{[6.43-25.96]}\end{array}$ & $\begin{array}{c}16.49 \pm 4.54 \\
{[5.91-25.70]}\end{array}$ & $\begin{array}{l}16.03 \pm 4.74 \\
{[6.44-25.29}\end{array}$ & $\begin{array}{c}16.61 \pm 4.77 \\
{[5.91-25.49]}\end{array}$ \\
\hline
\end{tabular}

${ }^{1}$ Mean environmental temperature; ${ }^{2}$ Mean minimum temperature; ${ }^{3}$ Mean maximum temperature; ${ }^{4}$ Relative humidity; ${ }^{5} \mathrm{Mean}$ evaporation; ${ }^{6}$ Mean sunshine hours; ${ }^{7}$ Mean solar radiation. 


\section{Forecast climatic indices}

Originally proposed by Ollerenshaw and Rowlands (1959), the Wet Day index (Mt) was later modified by Ollerenshaw $(1971,1973)$ and is expressed by the equation:

$$
\mathrm{Mt}=n(R-P+125) / 25
$$

where $n$ is the number of rain days, $R$ the rainfall in $\mathrm{mm}$, and $P$ the potential transpiration in $\mathrm{mm}$. For F. hepatica, in general, Mt values $\geq 100$ were initially considered to be sufficient for transmission in the UK, and as low as 80 for France (Ollerenshaw, 1971, 1973). Months with Mt values equal to or higher than that are potential high-risk periods for the incidence of the disease (critical value).

Mt was calculated for each month of each year producing a data set from which the following was obtained for each station: (i) monthly means for the 1990-2010 period; (ii) annual means for each year from 1990 to 2010; and (iii) annual means for the months of summer (June, July and August) and winter (December, January and February) for the seven periods of 1990-1992, 1993-1995, 1996-1998, 1999. 2001, 2002-2004, 2005-2007 and 2008-2010. Although Mt is known to furnish insufficiently accurate results due to its simplicity and the few climate factors on which its calculation is based (Fuentes et al., 1999) and is not able to differentiate between F. hepat$i c a$ and F. gigantica, this index was selected initially because the intermediate latitudes and low altitude of Punjab are not far away from those countries where Mt has previously been applied, thus enabling comparisons. For a more accurate assessment by differentiating between the two fasciolid species, the waterbudget-based system (Wb-bs) index, proposed by Malone et al. (1998), was calculated:

$$
\begin{gathered}
\text { Wb-bs }=(G D D \times D M), \\
\text { if }[R-(P E T \times 0.8)]>0+(G D D \times Z)[(R-P E T) / 25], \\
\text { if }(R-P E T)>0
\end{gathered}
$$

where $R$ is the rainfall, PET the potential evapotranspiration, $D M$ the days in month (here used as constant 30 periods to avoid the problem of the 28 days for February), $Z$ the number of surplus rain days in the month, and GDD the growing degree-days calculated as the average annual mean temperature minus the base development temperature for the liver fluke, which is of $10{ }^{\circ} \mathrm{C}$ for $F$. hepatica (Ollerenshaw and
Rowlands, 1959; Armour, 1975) and $16{ }^{\circ} \mathrm{C}$ for F. gigantica (Dinnik and Dinnik, 1963). The different risk values of that index, conventionally established for Ethiopia, were the following: $600=$ no risk; 601 $1,500=$ low risk; $1,500-3,000=$ moderate risk; and $>3,000=$ high risk (Yilma and Malone, 1998).

Data sets were also produced for Wb-bs for each Fasciola species in each station, the following averages being obtained: (i) monthly means for the 1990-2010 period; (ii) annual means for each year from 1990 to 2010, and (iii) annual summer and winter means for 1990-1992, 1993-1995, 1996-1998, 1999-2001, 2002-2004, 2005-2007 and 2008-2010.

\section{Seasonal, yearly and geographical assessment of the disease transmission risk}

Seasonality of the transmission risk was assessed by yearly curves of the mean monthly results for both indices (Mt without fasciolid species differentiation and Wb-bs with fasciolid species differentiation) for each one of the five stations. For the analysis of the climate change impact, the changing trends of fascioliasis risk for each station throughout the 1990-2010 period were assessed by using a linear model, adjusted versus time, of the $\mathrm{Mt}$ and $\mathrm{Wb}$-bs curves for the summer and winter according to the aforementioned seven year groups. Surface maps on disease transmission risk were constructed by means of the geostatistic programme Surfer version 10 for MS Windows (Golden Software; Golden, USA). This is a contour and surface modelling software package, which displays data to create maps and is useful for terrain modelling, bathymetric modelling, landscape visualization, surface analysis, contour mapping, gridding, watershed and three-dimensional (3-D) surface mapping. By modelling the mean annual $\mathrm{Mt}$ and $\mathrm{Wb}$-bs index values, maps were obtained, based on the kriging method (Delfiner, 1976) to infer possible risk variation degrees to areas proximal to the five stations and thus show the geographical distribution of the disease transmission risk throughout the Punjab province.

\section{Remote sensing data}

To further assess seasonality of transmission, the general response of vegetation was analysed by means of the normalized difference vegetation index (NDVI) images. This index offers maps in which vegetation is illustrated by variation of "greenness", in the range from -1.0 to 1.0 . This index has already proved to be significantly correlated with the geographic distribu- 
tion of fascioliasis, both in animals (Malone et al., 1998) and humans (Fuentes et al., 2001), as well as with seasonality of transmission (Yilma and Malone, 1998). A total of 14 10-day (decade) composite 1-km resolution NDVI images covering the whole province of Punjab were obtained from the PAK-SCMS (Pakistan Satellite Based Crop Monitoring System) Bulletin provided by SUPARCO (Pakistan Space and Upper Atmosphere Research Commission, SPARCENT, Islamabad, Pakistan), including each month from December 2010 to January 2012. The information used was obtained daily and consisted of $10-\mathrm{m}$ multispectral and 5-m panchromatic data from SPOT 5 (http://www.satimagingcorp.com/satellite-sensors/ spot-5.html), as well as from $250-\mathrm{m}$ resolution data from MODIS (http://modis.gsfc.nasa.gov).

\section{Animal and buman prevalence data}

Punjab fascioliasis prevalence data were obtained from literature sources (Table 1) and treated separately according to the fasciolid species in question, i.e. Fasciola sp. (when not specified), F. hepatica or F. gigantica (when specified). F. hepatica/F. gigantica intermediate forms have already been demonstrated in the Punjab province (Afshan et al., 2013), which means that fasciolid species identification may not always be made by simple visual observation as usually performed when carrying out extensive surveys of numerous animals (Periago et al., 2008). Additionally, prevalence data were also separately considered according to (i) each animal host species and humans; (ii) type of diagnostic technique applied (coprology, serology and histopathology); (iii) year (and months) of the study; and (iv) locality/district including altitude (Table 1).

\section{Statistical validation of index information}

Index validation was made by correlation analyses. Bivariant correlations (Pearson's) were calculated for monthly fascioliasis prevalence rates (\%) of both humans and livestock (sheep, goats, cattle and buffaloes), versus the monthly values obtained for each of the three indices (Mt, Wb-bs for F. hepatica and Wbbs for F. gigantica) for the whole year. Mono-seasonal correlation analyses were performed for each index for each pair of datasets by considering different time lags according to the minimum length variability of the Fasciola life cycle (Mas-Coma and Bargues, 1997). Only prevalence data from yearly surveys were considered. Point prevalence rates noted in many articles were not used to avoid introducing potential errors due to seasonality. To analyse transmission bi-seasonality, the correlation of NDVI with prevalence rates was assessed by dividing the year into the first semester (first half of the year) and the second semester (second half of the year), in order to facilitate value correspondence analyses. NDVI values of the first semester were correlated independently with the prevalence rates of the second semester. Likewise, NDVI values of the second semester were correlated independently with the prevalence rates of the first semester. Statistical analyses were carried out with SPSS Statistics 19. Results of Mt and Wb-bs were considered statistically significant when $\mathrm{P}<0.05$ and $\mathrm{P}<0.01$. Regression lines obtained for trend analyses were considered statistically significant when $\mathrm{P}<0.05$.

\section{Results}

\section{Analysis of climatic data}

The climatic factors that mainly influence fascioliasis transmission and prevalence (temperature, rainfall and humidity), produced by mean monthly graphs, climate diagrams and mean annual data throughout the 19902010 period, varied according to altitude. Differences between the stations mainly rely on precipitation, due to the proximity of Rawalpindi and Jhelum to the northern mountains of the Pir Panjal Range of the Great Himalayas (Figs. 1a and 1b). At higher altitudes (Rawalpindi and Jhelum), precipitation was higher and temperature lower, with the inverse at lower altitudes (Sargodha and Faisalabad). A marked mono-seasonality was detected with the winter months (December February) characterised by low temperatures and low precipitation, and the summer months (June-August) typified by high temperatures and high precipitation. The spring months (March-May) presented the lowest mean values of relative humidity $(\mathrm{RH})$, while the highest were recorded in July and August at higher altitudes and in November in the lowland plains.

\section{General fascioliasis risk by the $M t$ index}

In the study of the seasonal variation of the mean monthly values of the Mt index throughout the 19902010 period, pronounced differences were found when comparing the five stations. These differences were concentrated in the summer months and agree with the altitudinal pattern. Localities at higher altitudes show elevated transmission risk in those months, whereas no marked differences appeared dur- 
ing the remaining months suggesting that fascioliasis may not be a risk at this time or only sporadically by transmission by accumulated still viable metacercariae in the environment (Fig. 2). It should be considered that metacercariae may be viable for up to 48 weeks (Valero and Mas-Coma, 2000). However, the small risk peak presented by the two altitude stations of Rawalpindi and Jhelum in March should not be neglected. Rawalpindi, Jhelum and Lahore showed epidemic risk levels from the beginning of July to the end of August; while Sargodha and Faisalabad, situated at lower altitudes and presenting less rainfall during July and August (Table 2), show Mt values hardly reaching the level needed to support transmission.

In the analysis of the yearly variation of the mean Mt values in each locality for the seven year groups, regression lines did not show any trend in the winter (graph not shown). In summer, the northern hilly areas (Rawalpindi and Jhelum) showed a clear decreasing trend of risk, whereas a hardly noticeable increase trend characterised the data from the lowland stations (Sargodha and Faisalabad) (Fig. 3). However, none of these trends presented significant P-values. Geographically, the same results appeared in the maps with no differences in winter, but with the fascioliasis transmission risk decreasing and moving northward in the northern highlands in the summer, while the increase was barely detectable in the southern lowlands (maps not shown).

Discriminating between $\mathrm{F}$. hepatica and $\mathrm{F}$. gigantica infection risks by the Wb-bs index

In the study of the seasonal variation of the mean monthly values of the Wb-bs index throughout the 1990-2010 period, values were obtained for F. hepati$c a$ and F. gigantica. Within Wb-bs values for each species, differences were found when comparing the five stations. These differences concern the highest peak corresponding to the summer months and agreeing with the altitudinal pattern (Fig. 4). Localities at higher altitudes showed elevated transmission risk in these months, whereas no obvious differences appeared during the remaining months of the other three seasons. The highest station in Rawalpindi showed the lowest transmission risk for both fasciolids throughout these three seasons.

The yearly variation of the mean Wb-bs values in each locality was analysed for each Fasciola species for the seven year groups. In the winter, the index for both $F$. hepatica and F. gigantica showed increasing trends of fascioliasis risk in all stations, although none

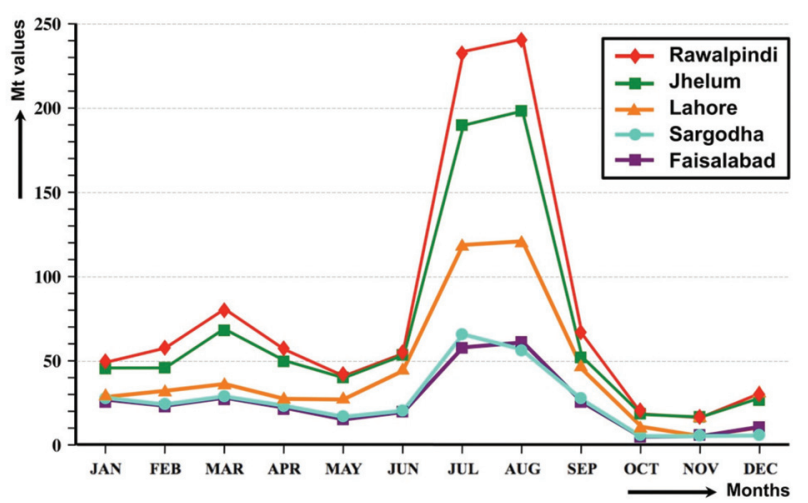

Fig. 2. Mean monthly values of the wet-day indicator $(\mathrm{Mt}$ index) in Punjab province throughout the 1990-2010 period. Values based on measurements at the five meteorological stations of Punjab province.

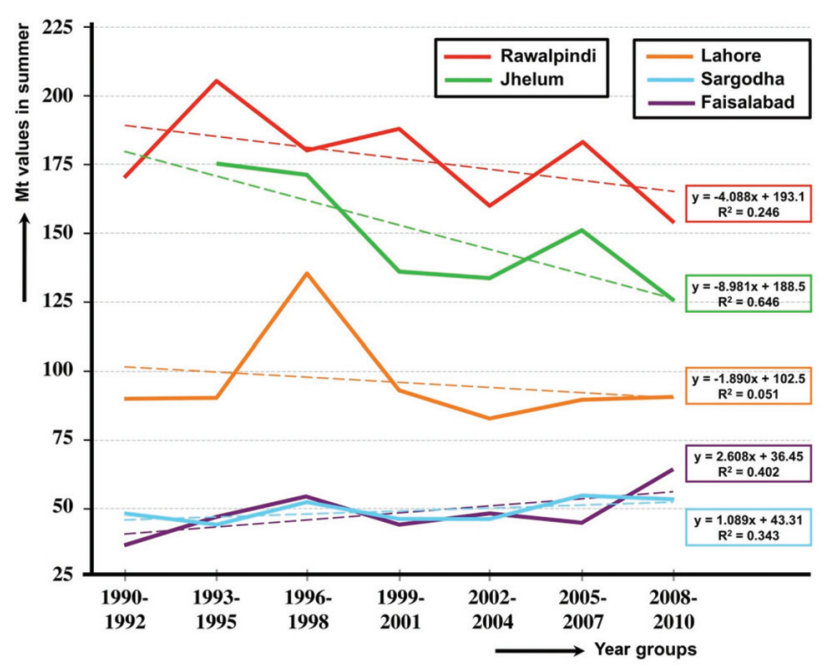

Fig. 3. Long-term trends and respective regression lines of the wet-day indicator (Mt index) for the summer months in Punjab province. Values based on measurements at the five meteorological stations of Punjab province over seven three-year groups in the 1990-2010 period.

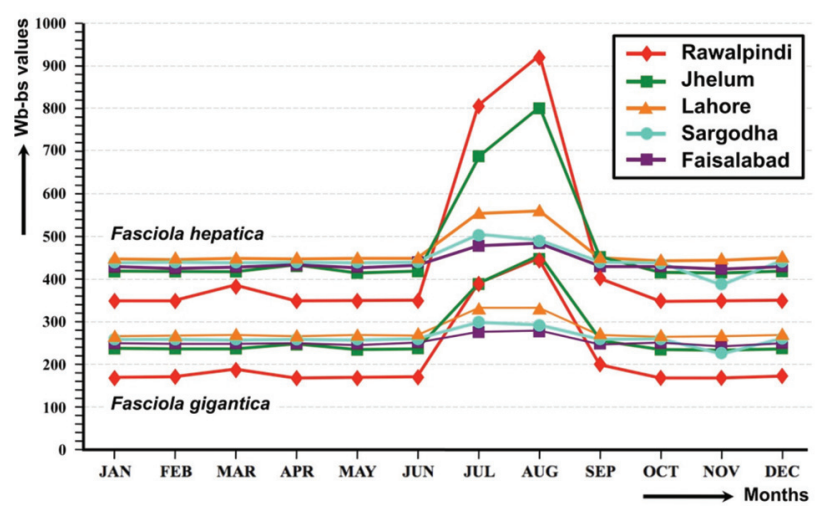

Fig. 4. Mean monthly values of the water-budget-based system indicator (Wb-bs index) for F. hepatica and F. gigantica in Punjab province. Values based on measurements at the five meteorological stations studied in Punjab province throughout the 1990-2010 period. 

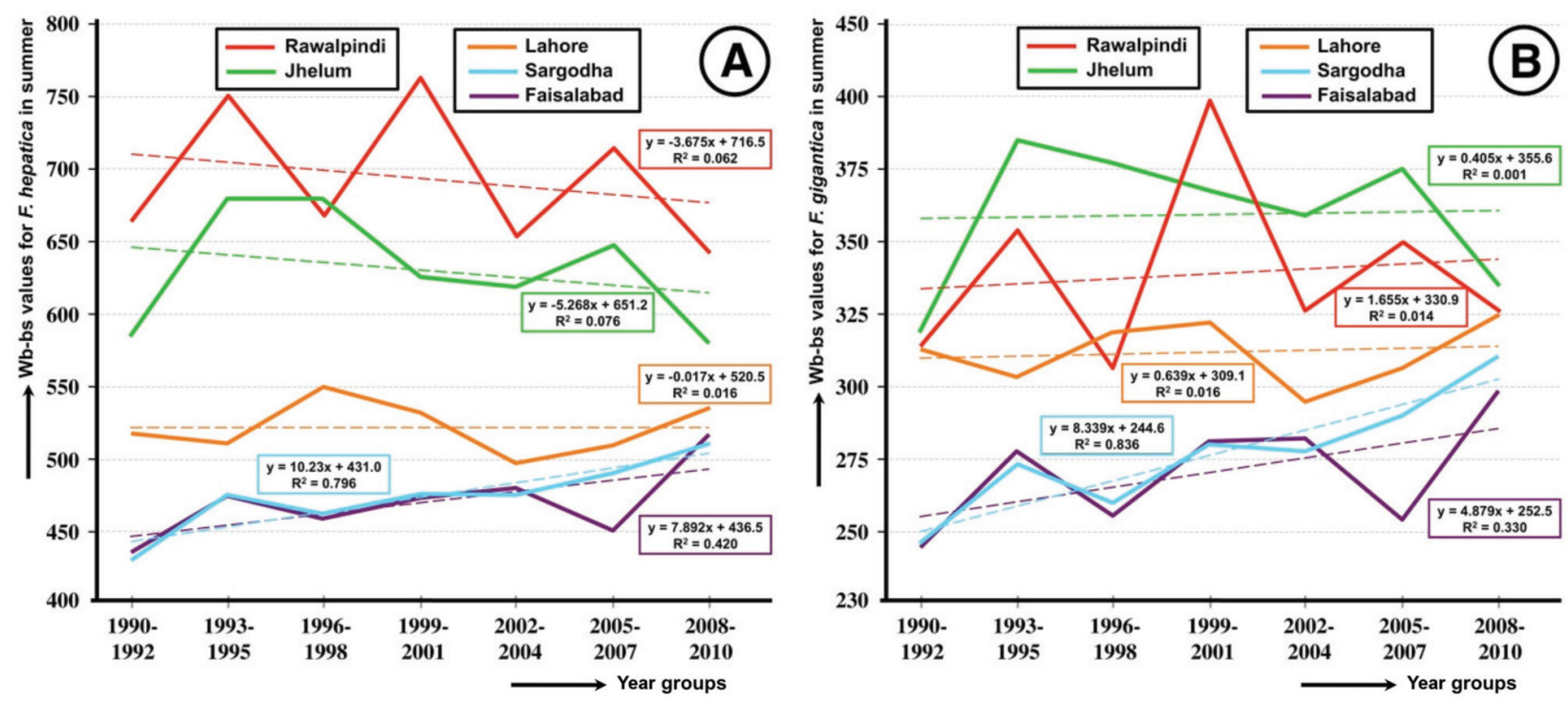

Fig. 5. Long-term trends and the corresponding regression lines of the Water-Budget-Based System indicator (Wb-bs index) in the summer months for Fasciola hepatica (a) and F. gigantica (b) in Punjab province. Values based on measurements at the five meteorological stations of Punjab province over seven three-year groups in the 1990-2010 period.

appeared significant (curves not shown). In the summer, Wb-bs for F. hepatica showed decreasing trends for the two altitudinal areas, no modification for the Lahore area, and markedly increasing trends for Sargodha and Faisalabad, the former statistically significant $(\mathrm{P}<0.05)$ (Fig. 5a). In the same Wb-bs analysis for F. gigantica in the summer, the statistically significant trend of increase of disease transmission risk in Sargodha should be emphasised $(\mathrm{P}<0.05)$. The station of Faisalabad also showed an evident, increasing trend, although not significant (Fig. 5b). In the two maps of the Wb-bs values for each fasciolid species, the highest transmission risk appeared throughout the whole 1990-2010 period (Figs. 6a and 6b) in the north-eastern part of Punjab province, with a decrease towards the Punjab Plain both southward and westward. Interestingly, Lahore was seen to be included in this high-transmission risk area, which extended up to Sargodha for F. gigantica, thus including the area of human infection (Fig. 6b).
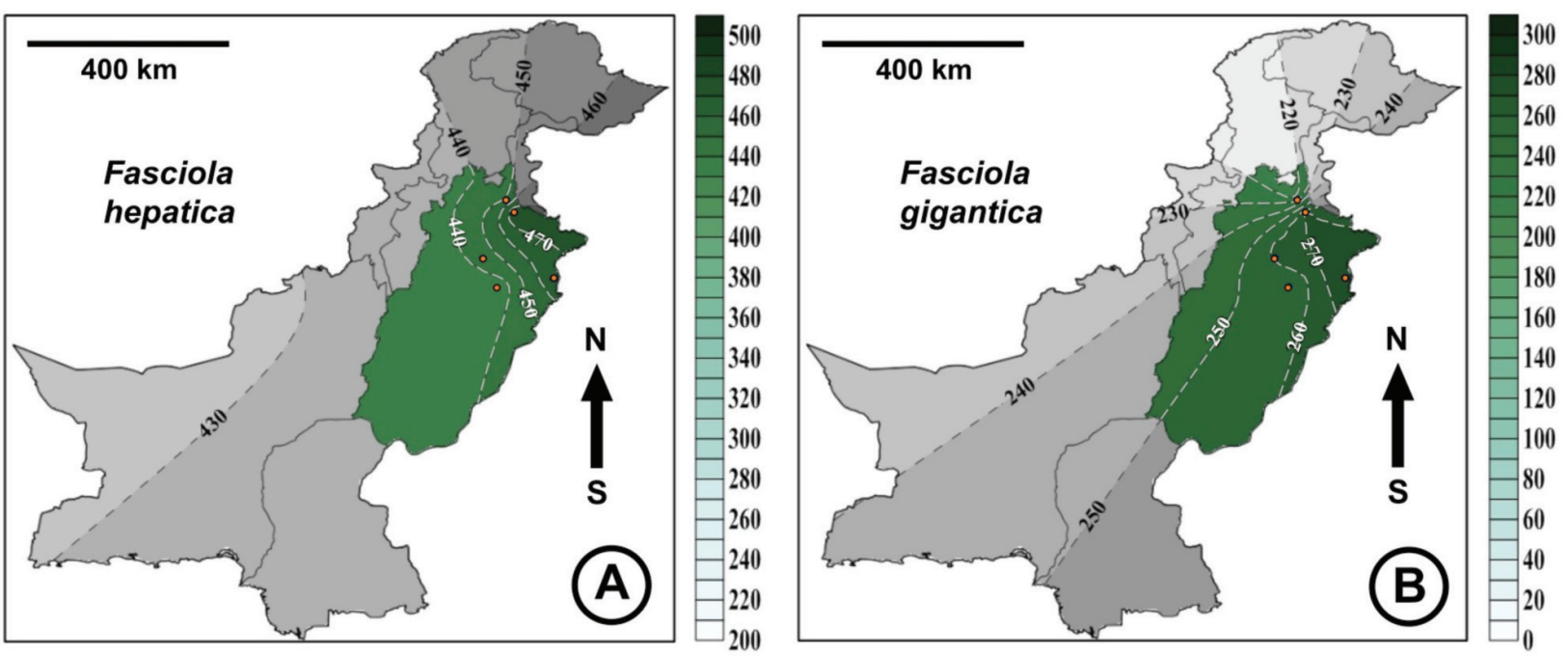

Fig. 6. Geographical distribution of fascioliasis transmission risk for F. hepatica (a) and F. gigantica (b) in Punjab province, Pakistan. 
Assessment of fascioliasis distribution heterogeneity by the vegetation index

The Punjab area was heterogeneous throughout the whole year (Figs. 7 and 8). The sequential, comparative analysis of the 14 monthly NDVI maps illustrates how pronouncedly the land changes with the seasons. At the end of the dry season, May proved to be the month with less green colour throughout the Punjab plain, followed by June when the vegetation decreased in the northern highlands. The NDVI maps show how the Indus River basin and that of the large tributaries only here and there showed light vegetation in these two months. In contrast, September demonstrated high NDVI values in both the highlands and the whole Punjab plain, as it corresponds to the end of the rainy season, the monsoon manifesting itself by remarkably high rainfall. The synchronised highlands and Punjab plain September NDVI peaks should be mentioned here.
In between the aforementioned monthly extremes, whereas the June-August period showed a logical gradual increase, the months from October to April did not show gradually decreasing NDVI degrees. After the gradual decrease during October-December, there another rise of NDVI values appeared but differed depending on area:

(i) in the highlands (Islamabad and Rawalpindi) a vegetation peak appeared in April after the gradual increase starting in January (Fig. 8) due to the small rains of December and the gradually increasing temperatures at these altitudes; and

(ii) in the Punjab plain, this second NDVI rise became evident during the January-March period (Fig. 8); this February peak appeared two months before the April one in the highlands, and it was even higher than the September one.

In the northern part of the province, the mountainous triangle eastward from Islamabad and Rawalpindi, and including these two cities, appeared
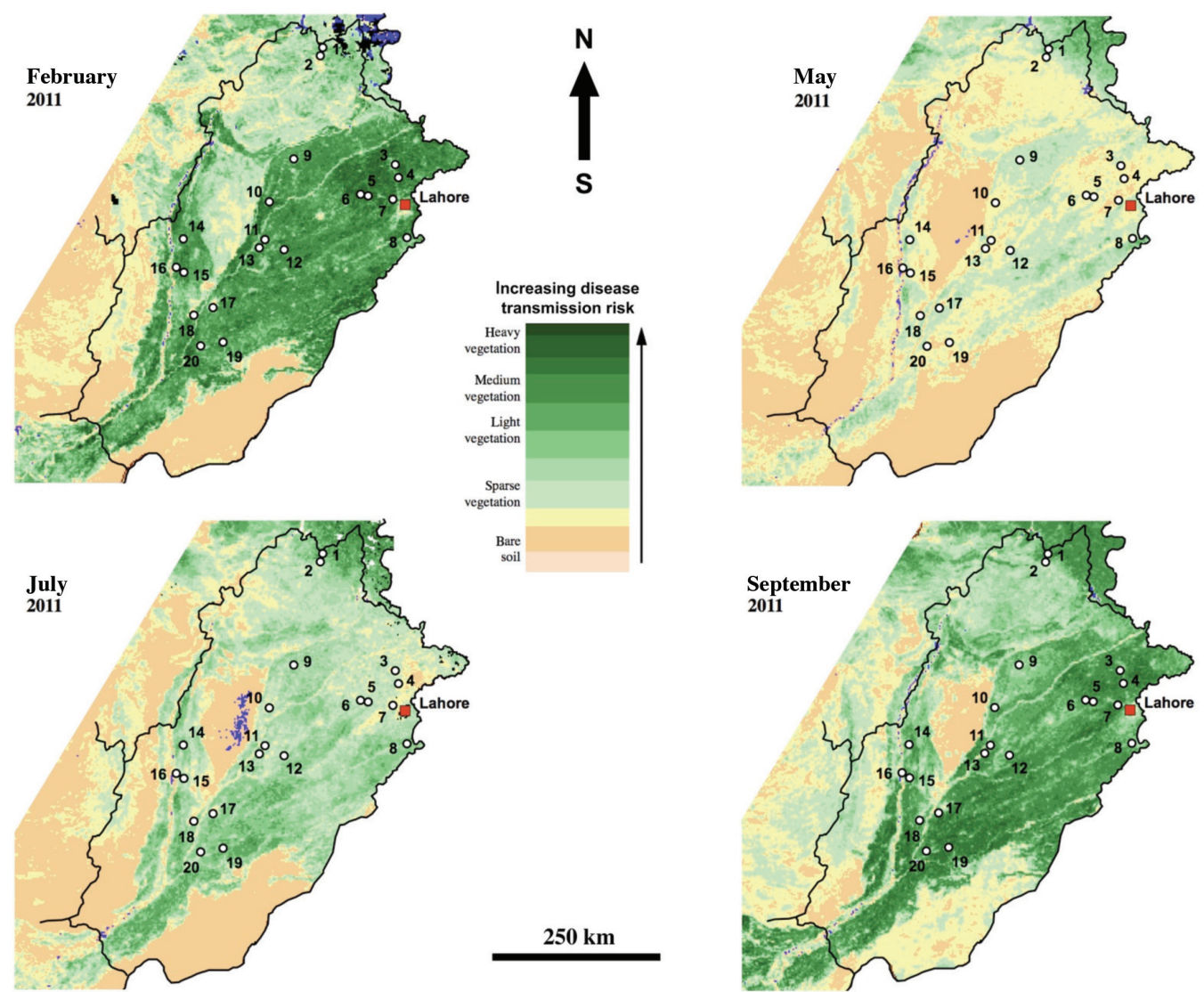

Fig. 7. NDVI map of Punjab province showing situations in the different seansons of year 2011. February represents the vegetation peak in winter due to irrigation with May as the end of the dry season. July is the intense time of vegetation (more so in the southern mid-half than in the northern mid-half of the Punjab plain) with September representing the peak of rainy season. The red square shows the location of the city of Lahore, in whose western lowlands human infection has been reported. The white circles refer to localities where Fasciola infection in livestock has been reported: Islamabad (1), Rawalpindi (2), Gujranwala (3), Kamoke (4), Muridke (5), Sheikhupura (6), Shahdara (7), Kasur (8), Sargodha (9), Mor Mandi (10), Jhang (11), Toba Tek Singh (12), Shorkot (13), Layyah (14), Kot Addu (15), Farooqia (16), Dunya Pur (17), Muzaffargarh (18), Lodhran (19) and Jalalpur (20). 


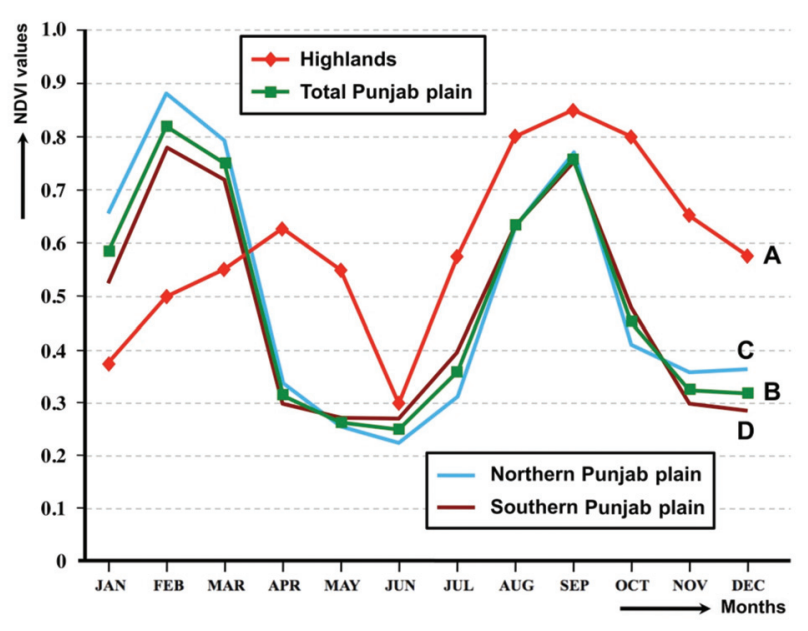

Fig. 8. Annual variation of the mean monthly NDVI values in Punjab province in 2011 for localities where Fasciola infection in livestock has been reported. (a) The highlands, which includes Islamabad (1) and Rawalpindi (2); (b) Punjab plain, which includes Gujranwala (3), Kamoke (4), Muridke (5), Sheikhupura (6), Shahdara (7), Kasur (8), Sargodha (9), Mor Mandi (10), Jhang (11), Toba Tek Singh (12), Shorkot (13), Layyah (14), Kot Addu (15), Farooqia (16), Dunya Pur (17), Muzaffargarh (18), Lodhran (19) and Jalalpur (20); (c) Northern Punjab plain including localities 3 to 10 ; and (d) Southern Punjab plain including localities 11 to 20 .

to have the appropriate characteristics for high fascioliasis transmission. Southward, the Potwar plateau showed middle transmission risk only in summer months (Fig. 7). Throughout the Punjab plain, despite its topographic uniformity (Fig. 1B) and rainfall homogeneity, the NDVI maps show a remarkably heterogeneous surface (Fig. 7). Throughout the western part, the vegetated surface appeared to be related to the Indus River basin. However, the largest vegetation area corresponded to the eastern, wide basin created by the Jhelum, Chenab, Ravi and Sutlej tributaries featuring well-developed canal systems for irrigation. Three large areas appeared to be without any or with only very scarce vegetation: (i) the Sind Sagar Doab in the northern part between the two basins; (ii) the Sulaiman Range in Rajanpur westward from the Indus basin; and (iii) the Cholistan, the Pakistani part of the Thar Desert in Bahawalpur up to the Indian border in the South. All localities presenting infected livestock appeared within the river basins, in highly vegetated areas (Fig. 7). Additionally, a comparison between northern and southern Punjab plain showed that in November-April NDVI values are higher in the northern part, whereas during the May-July period of low NDVI values this frame reverses, NDVI values in the southern part becoming higher (Fig. 8).

\section{Index/prevalence correlation results}

Statistically significant results were obtained between the values of the Mt, Wb-bs and NDVI indices and the fascioliasis prevalence rates known in humans and livestock when the Pearson's correlation was applied (Table 3). These correlation results illustrate the accuracy of the indices used. All correlations analysed concerned the Punjab plain only, as no appropriate monthly prevalence data from the highlands (Islamabad, Rawalpindi and northern neighbouring areas) covering the full year could be found in the literature.

\section{Discussion}

\section{Geographical distribution of fascioliasis risk}

In the extreme north of the province, the mountainous triangle eastward from Islamabad appeared as a high-risk area according to the Mt and NDVI values. However, Wb-bs did not show this area as the highest risk, which agrees with the gradual decreasing risk according to the Mt index in the 1990-2010 period, the lowering NDVI values in the non-rainy season, and prevalence rates of less than $5 \%$ reported in sheep and goats (Table 1) (Gadahi et al., 2009).

Galba truncatula, the lymnaeid transmitting F. hepatica, has never been found in Pakistan below the altitude of 4,000 feet (1,219 m) (Kendall, 1954). This means that the pure transmission of F. hepatica in the Punjab province is a priori impossible. Consequently, F. hepatica reports in livestock from Punjab should concern (i) whether cases in nomadic ruminants having been infected in altitudes higher than $1,200 \mathrm{~m}$ and afterwards transported to the Punjab lowlands, or (ii) young, still small-sized F. gigantica specimens could have been confused with F. hepatica, without ruling out (iii) the potential intermediate $F$. hepatica-like forms able to be transmitted by the F. gigantica-specific lymnaeid Radix auricularia (synonyms: Lymnaea rufescens, L. acuminata, L. gedrosiana and L. persica). Despite this, R. auricularia, Lymnaea luteola, L. acuminata and L. rufescens together with G. truncatula, have been reported to be present and involved in fascioliasis transmission in lowland districts such as Gujranwala, Lahore, Sheikupura, Sargodha, Jhang and Faisalabad (Buriro and Chaudhry, 1981; Tanveer, 1990; Maqbool et al., 2003). Misidentifications with $R$. auricularia may not be ruled out. Even small young $R$. auricularia forms might be confused with G. truncatula, although popu- 
Table 3. Bivariant correlations (Pearson's correlation) between monthly values of the Mt, Wb-bs and NDVI indices and monthly values of the fascioliasis prevalence $(\%)$ in humans and livestock in Punjab province, Pakistan.

\begin{tabular}{|c|c|c|c|c|c|}
\hline $\begin{array}{l}\text { Locality of index } \\
\text { analysed }\end{array}$ & $\begin{array}{l}\text { Definitive host } \\
\text { (number and species) }\end{array}$ & $\begin{array}{l}\text { Locality or district of the } \\
\text { definitive hosts }\end{array}$ & $\begin{array}{l}\text { Prevalence study } \\
\quad \text { (reference) }\end{array}$ & $\begin{array}{l}\text { Pearson's } \\
\text { correlation }\end{array}$ & $\begin{array}{l}\text { Significance } \\
\text { level (P-value) }\end{array}$ \\
\hline \multicolumn{6}{|l|}{$\mathrm{Mt}^{1}$} \\
\hline Lahore & 840 sheep and 660 goats & Toba Tek Singh & Khan et al. (2010) & 0.643 & 0.5 \\
\hline Lahore & 1,140 cattle and 1,140 buffaloes & Toba Tek Singh & Khan et al. (2010) & 0.578 & 0.5 \\
\hline Lahore & 1,720 buffaloes in livestock farm & $\begin{array}{l}\text { Lahore, Gujranwala, } \\
\text { Sheikhupur, Sargodha, Jhang } \\
\text { and Faisalabad }\end{array}$ & Maqbool et al. (2002) & 0.782 & 0.01 \\
\hline Lahore & 360 humans & Lahore district* & Qureshi (2008) & 0.657 & 0.5 \\
\hline Faisalabad & 840 sheep and 660 goats & Toba Tek Singh & Khan et al. (2010) & 0.620 & 0.5 \\
\hline Faisalabad & 7,200 humans & Northern Punjab plain** & Qureshi (2008) & 0.592 & 0.5 \\
\hline \multicolumn{6}{|l|}{ Wb-bs ${ }^{2}$} \\
\hline $\mathrm{Fh} / \mathrm{Fg}$ Lahore & 840 sheep and 660 goats & Toba Tek Singh & Khan et al. (2010) & $0.705 / 0.700$ & $0.5 / 0.5$ \\
\hline $\mathrm{Fh} / \mathrm{Fg}$ Faisalabad & 840 sheep and 660 goats & Toba Tek Singh & Khan et al. (2010) & $0.592 / 0.596$ & $0.5 / 0.5$ \\
\hline $\mathrm{Fh} / \mathrm{Fg}$ Faisalabad & 1,140 cattle and 1,140 buffaloes & Toba Tek Singh & Khan et al. (2010) & $0.652 / 0.649$ & $0.5 / 0.5$ \\
\hline $\mathrm{Fh} / \mathrm{Fg}$ Faisalabad & 1,720 buffaloes in livestock farm & $\begin{array}{l}\text { Lahore, Gujranwala, } \\
\text { Sheikhupur, Sargodha, Jhang } \\
\text { and Faisalabad }\end{array}$ & Maqbool et al. (2002) & $0.827 / 0.815$ & $0.01 / 0.01$ \\
\hline $\mathrm{Fh} / \mathrm{Fg}$ Faisalabad & 7,200 humans & Northern Punjab plain** & Qureshi (2008) & $0.888 / 0.889$ & $0.01 / 0.01$ \\
\hline $\mathrm{Fh} / \mathrm{Fg}$ Faisalabad & 360 humans & Lahore district* & Qureshi (2008) & $0.773 / 0.774$ & $0.01 / 0.01$ \\
\hline \multicolumn{6}{|l|}{$\mathrm{NDVI}^{3}$} \\
\hline Layyah & 840 sheep and 660 goats & Toba Tek Singh & Khan et al. (2010) & 0.955 & 0.01 \\
\hline Layyah & 1,720 buffaloes in livestock farm & $\begin{array}{l}\text { Lahore, Gujranwala, } \\
\text { Sheikhupur, Sargodha, Jhang } \\
\text { and Faisalabad }\end{array}$ & Maqbool et al. (2002) & 0.938 & 0.01 \\
\hline Sarghoda & 7,200 humans & Northern Punjab plain** & Qureshi (2008) & 0.989 & 0.01 \\
\hline Sarghoda & 1,140 cattle and 1,140 buffaloes & Toba Tek Singh & Khan et al. (2010) & 0.969 & 0.01 \\
\hline Jhang & 1,140 cattle and 1,140 buffaloes & Toba Tek Singh & Khan et al. (2010) & 0.855 & 0.5 \\
\hline Jhang & 360 humans & Lahore district* & Qureshi (2008) & 0.958 & 0.01 \\
\hline
\end{tabular}

${ }^{1}$ Wet days; ${ }^{2}$ Water-budget-based system for F. hepatica/F. gigantica $(\mathrm{Fh} / \mathrm{Fg}) ;{ }^{3}$ Normalized difference vegetation index; ${ }^{*}$ Lahore district: rural localities of Scheme no. 2, Bhutto colony, Sheikhupura road, Khairdin park, Misri Shah and Siddiquia colony; **Northern Punjab plain: areas of Sheikhupura, Gujranwala, Kasur, Shahdra, Kamonki and Muridke.

lations of the latter deriving from specimens swept away by the waters from the highlands may perhaps shortly survive during cooler periods in the Punjab plain lowlands.

The Potwar plateau appears as a mid-risk area, while the north-eastern area between Lahore city and the northern province border is more complicated. It appears to be of mid-risk according to $\mathrm{Mt}$, high risk according to $\mathrm{Wb}$-bs, and varying from no risk during the dry season to high risk during the rainy season according to the NDVI. Although the rest of the wide Punjab plain is homogeneous from the topographic and rainfall points of view (see rainfall region no. 2 in Hussain and Lee, 2009), it appears heterogeneous concerning the fascioliasis risk due to: (i) the river Indus, its four tributaries and their five basins; (ii) the dry northern part of the Sind Sagar Doab between the rivers Indus in the West and Chenab-Jhelum in the 
east; and (iii) the southern mid-part of the Punjab plain, including the dry Cholistan area in the east and strip of land between the Indus basin and the province border in the west (Fig. 1b). This heterogeneity appears well illustrated by NDVI when comparing the dry and wet seasons (Fig. 7).

\section{Critical values of forecast climatic risk indices}

The critical value of Mt could be conventionally designated as 55 or 60 (Fig. 2). This is pronouncedly less than the critical value of 100 for UK and 80 for France (Ollerenshaw, 1971, 1973). However, in Europe there is only F. hepatica, whereas this is the first time that this index has been applied to F. gigantica; and the lower latitudes of Pakistan may also have an influence. This critical Mt value would have worked well in this study if there would not have been the Indus basin river irrigation system, which distorts fascioliasis risks throughout the Punjab plain.

The overlap of the presence of infection by both Fasciola species in livestock covering almost the entire Punjab province makes it difficult to apply the critical Wb-bs values (Fig. 4). The maximum temperature threshold of $F$. hepatica, usually put at $26^{\circ} \mathrm{C}$ (MasComa and Bargues, 1997), indicates that pure F. hepatica transmission may only happen sporadically and, if at all, in the northern Punjab highlands. This suggests that the critical Wb-bs value for F. hepatica should be put around 600. With regard to F. gigantica, a critical Wb-bs value of 250 indicates transmission throughout the Punjab plain at least if dams, barrages, canals and artificial irrigation would not be there. A critical value of 600 agrees with the one established for Ethiopia by Yilma and Malone (1998), where the two fasciolid species are present at different elevation ranges and predicted to coexist at intermediate altitude zones. In Punjab, the existence of intermediate forms (Afshan et al., 2013) may, however, give rise to a continuum between the extreme requirements of pure $F$. hepatica and those of pure F. gigantica presence.

\section{Livestock influencing prevalence rates}

In Punjab, livestock is restricted to the mid-sized ovicaprines sheep and goats and the large ruminants cattle and buffaloes. Although different livestock species represent similar infection sources (Valero and Mas-Coma, 2000; Valero et al., 2001), animal species susceptibility should be considered. The livestock species influences fluke development and egg production and shedding (Valero et al., 1998, 2002, 2009).
Thus, liver fluke susceptibility of these two ruminant groups is very different. This means that prevalence rates do not allow an appropriate comparison between mid-sized ovicaprines and large ruminants, and neither between F. hepatica and F. gigantica infections. The infected livestock include buffalo (prevalence rates of $8-32 \%)$, cattle $(3-70 \%)$, sheep $(4-40 \%)$ and goats $(0.5-60 \%)$ (Durrani et al., 1981; Masud and Majid, 1984; Iqbal et al., 1986; Hayat et al., 1986; Malik et al., 1995; Razzaq et al., 2002) (other examples in Table 1).

Livestock management has also proved to be related to different prevalence rates in the same host species in Punjab. Thus, a study on 21,928 buffaloes performed in slaughter houses, livestock farms, veterinary hospitals and on household buffaloes, showed differences in infection rates of $25.6 \%, 26.2 \%$, $13.7 \%$ and $10.5 \%$, respectively (Maqbool et al., 2002). Other factors influencing prevalence rates in Punjab are the bathing system (stagnant ponds, rivers/canals and tap water), the farming system (mixed farming with sheep/goats or large ruminants only), open grazing or stall feeding, without forgetting the common (but not complete) use of fasciolicide treatment with either oxyclozanide, rafoxabide and triclabendazole (Khan et al., 2009).

\section{Effects of anthropogenic modifications of the environ- ment}

A marked mono-seasonality with a very evident peak in July and August was indicated by $\mathrm{Mt}$ and $\mathrm{Wb}$ bs values (Figs. 2 and 4). An additional small peak appeared in March only at high altitudes. Since there is no information in the literature about fascioliasis prevalence curves throughout the year in Punjab altitude areas, this March peak cannot yet be independently supported. However, the NDVI values indicated a marked bi-seasonality (Fig. 8). A peak in September and with the lowest values in May-June agree with Mt and Wb-bs results, as expected from a delayed plant growth under appropriate climatic conditions. Interestingly, the intense January-March peak in the Punjab plain and the less intense March-May peak in the highlands, revealed by the NDVI, suggest that other water sources not detected by $\mathrm{Mt}$ and Wb-bs obtained from the stations would be involved:

(i) given that there is no rainfall in the Punjab plain outside the mid-May to mid-August period, water in the winter derives from the artificial irrigation systems; increased irrigation activity through extensive canalization allows for another period 
of lymnaeid activity; and

(ii) the secondary NDVI peak of March-May in the highlands corresponds to the vegetation response to the small rainfall peak of December and to water flowing from more intense December rainfall occurring in the mountains north of Punjab; irrigation, and not rainfall, explains the lack of NDVI synchrony in the January-May period between the highlands and the plain (Fig. 8).

A patent bi-seasonality was found in sheep, goats, cattle and buffaloes from Toba Tek Singh district, in which both F. hepatica and F. gigantica showed March peaks of presence almost as high as in October. Both peaks appeared very high for F. gigantica, whereas not even half as high for F. hepatica (Khan et al., 2010). Bi-seasonality, with a small January peak and a high September peak, was detected in buffaloes from rural localities of Lahore district and areas of northern Punjab plain (Qureshi et al., 2005a; Qureshi, 2008; Qureshi and Tanveer, 2009). Similarly, two prevalence peaks appeared in spring (March-April) and autumn (September-October) in buffaloes from slaughter houses, livestock farms, veterinary hospitals and household buffaloes from different districts of the Punjab plain (Maqbool et al., 2002). Bi-seasonality also occurs in other countries of the Northern Hemisphere, such as the spring and autumn transmission interrupted by lymnaeid lethargy during the cold winter and aestivation during the hot summer in Europe (Fuentes et al., 1999). A mono-seasonality with only one peak in December has, however, been described in cattle and buffaloes from different districts of the Punjab plain (northern Sargodha and Jhang, and southern Muzaffargarh, Lodhran and Layyah) (Khan et al., 2009). Thus, the comparison between small and large ruminants from the same area was useful as it showed why cattle and buffaloes are not as good as host species as sheep and goats for illustration of transmission seasonality (Khan et al., 2010).

Flooding of the rivers due to intense summer monsoons may also distort the seasonal pattern in the Punjab plain in given years (Kahn et al., 2010). $R$. auricularia is well known for its capacity to take advantage of flooding events when the water levels stay high for a long time. Indeed, different local population dynamics of $R$. auricularia, the only lymnaeid species in the hot lowlands, linked to different water body types, may explain the coexistence of fascioliasis transmission mono-seasonality (with the winter prevalence peak due to the August-September transmission peak) related to only rainfall and bi-seasonality related to annual overlap of rainfall and irriga- tion in different seasons (with autumn and spring prevalence peaks resulting from the AugustSeptember and February-March transmission peaks, respectively). Seasonal variations of environmental factors have already been mentioned to affect lymnaeid populations in Punjab plain (Tanveer and Khan, 1989; Maqbool et al., 2003) and the dynamics described above probably operate throughout the topographically uniform endemic areas here. $R$. auricularia prefers permanent water bodies with abundant vegetation. Most favoured habitats are still, or slightly moving, water, e.g. large lakes (particularly where any water movement is checked by reed-beds) and seepage areas from irrigation canals. There is considerable mortality of adult snails during autumn and winter as they do not resist drought. However, these snails may remain alive in a humid atmosphere in absence of water and may be present permanently in habitats, which become dry at intervals (Kendall, 1954). Thus, irrigation may give rise to an additional lymnaeid activity period per year resulting in fascioliasis transmission locally as long as temperatures do not decrease below the F. gigantica temperature threshold of $16{ }^{\circ} \mathrm{C}$. Moreover, water stocking at the level of the main dam reservoirs and barrages and subsequent canal supply may also give rise to water availability distorting the periodicity picture marked by rainfall.

\section{Effects of climate change on long-term fascioliasis risk trends}

Climate change influences in Pakistan include a 10$15 \%$ decrease of precipitation in hyper arid plains plus an increase of the summer and winter precipitation in the northern part of the country (Farooq and Kahn, 2004). Additionally, changes of future water availability must take into account the predicted glacier melting (Rees and Collins, 2004) and forecasts of fewer rains in summer and more in winter (IPCC, 2001). Global warming will yield additional flows of the order of 5.2 million acre feet $(\mathrm{MAF})^{1}$ annually (Basharat and Hashmi, 2010). Moreover, there might be an $8-24 \%$ increase in water delivered by future South Asian monsoons (IPCC, 2001).

The analysis of Mt and Wb-bs throughout the 19902010 period does not suggest any significant change in the long-term fascioliasis risk trend for the winter

\footnotetext{
${ }^{1}$ The amount of water covering one acre to the depth of one foot unit (a measure used for irrigation).
} 
months, although there might be a potential slight increase. On the contrary, the results point in the direction of evident trend modifications for the summer months. Despite the non-significant $\mathrm{P}$ values, the $\mathrm{Mt}$ and Wb-bs indices for $F$. hepatica support predictions of a progressive trend towards less transmission risk in the northern hilly areas of Punjab province. However, it should be highlighted that the agreement of Mt, Wb-bs for F. hepatica and Wb-bs for F. gigantica showed a trend of increasing risk by the two fasciolid species in Sargodha and Faisalabad lowlands (Figs. 3 and 5), the results for Sarghoda being statistically significant. This suggests that localities at low altitudes may reach higher prevalence levels in the future if the present weather trend continues. Climate change may thus give rise to higher fascioliasis prevalence rates throughout the Punjab province: in Punjab plain for the summer as indicated by the forecast climatic indices, and in the northern highlands due to increased water flow due to more winter rains and deglaciation. Thus, disease bi-seasonality may become more marked in the future.

\section{Human infection risk in Punjab province}

The studies on human fascioliasis have so far only been performed in Lahore district and neighbouring areas. Direct faecal examination, carried out from April 2003 to March 2005, showed 1.2\% total prevalence (85 infected out of 7,200 subjects), mostly in subjects below the age of 20 years in Gujranwala, Kasur, Shahdra, Kamonki and Muridke (Qureshi et al., 2005a; Qureshi, 2008). In subsequent surveys from April 2006 to March 2007, 18 stool samples from 360 subjects $(5.0 \%$ prevalence) and 27 blood samples analysed by indirect haemaglutination $(7.5 \%)$ were positive, again mostly in young individuals, from the rural localities of Siddiquia colony, Bhutto colony, Scheme no. 2, Misri Shah, Khairdin Park and Sheikhupura road in Lahore district (Qureshi et al., 2005b; Qureshi, 2008). Both aforementioned studies showed bi-seasonality, with one prominent peak in August and small one in January, i.e. being clearly parallel with prevalence curves obtained in buffaloes by the same diagnostic techniques from the same geographical origins and same periods (Qureshi et al., 2005a,b; Qureshi, 2008; Qureshi and Tanveer, 2009).

Results suggest a human disease situation giving cause for concern when considering the concentration of infection in children and young subjects and the following highlights:

(i) given the low sensitivity of the diagnostic tech- niques used (Valero et al., 2009, 2012a) and serological tests (Espinoza et al., 2007; Valero et al., $2012 \mathrm{~b}$ ), the prevalence rates found may underestimate the real situation;

(ii) the human infections were located in a wide area of the highest transmission risk according to $\mathrm{Wb}$ bs, and with pronounced bi-seasonality and a risk in February even higher than that in September according to NDVI;

(iii) moreover, these localities are found between Lahore and Sargodha, namely the area showing a significant trend of increasing fascioliasis risk due to climate change; and

(iv) human fascioliasis in other areas of the Punjab plain cannot be ruled out, as forecast indices indicate that infection risk in areas of central and southern Punjab plain is similar to that of localities where human infection has been found.

\section{Conclusions and recommendations}

The combined use of Mt, Wb-bs and NDVI have proven to be appropriate for the assessment of fascioliasis risk areas and seasonality in Punjab province, allowing a complete analysis in a heterogeneous epidemiological situation including bi-seasonality with one peak related to rainfall and another peak related to irrigation. The finding of bi-seasonality gainsays the current belief in epidemiological homogeneity.

Fascioliasis in Punjab is markedly different from that of the Bolivian Altiplano where water availability for disease transmission only depends on rainfall (Fuentes et al., 1999, 2001), and from Cambodia where transmission depends on artificial irrigation up to such a level that rainfall does not even need to be considered in the remote sensing GIS models (Tum et al., 2004, 2007).

The results illustrate how climate change and anthropogenic environment modifications are influencing fascioliasis risk. The economic importance of livestock in Punjab makes this phenomenon to be given forecast priority henceforth. In Pakistan, animal fascioliasis is generally controlled by chemotherapy. According to results and basing on international discussions (FAO, 1994), the following control scheme is recommended:

(i) a first preventive-curative treatment in FebruaryMarch in the Punjab plain followed by treatment in April-May in the highlands;

(ii) a second preventive-curative treatment in September-October throughout the endemic areas of the province. This treatment is crucial; and 
(iii) an intermediate prophylactic treatment at the end of the dry season (June) when development of free-living stages and intramolluscan fluke phases are retarded and reproduction and activity of the snails is minimum. If there are economic restrictions, this intermediate prophylactic treatment can be avoided.

For humans, priorities should include surveys on populations inhabiting the central and southern high risk areas of Punjab plain with repeated surveys in northern Punjab plain with sensitive and specific diagnostic techniques to assess the real situation.

\section{Acknowledgements}

Studies funded by projects no. SAF2010-20805 of the Ministry of Science and Innovation, Madrid, Spain; by the Red de Investigación de Centros de Enfermedades Tropicales RICET (project no. ISCIII-RETIC RD06/0021/0017 of the Programa de Redes Temáticas de Investigación Cooperativa RETICS/ FEDER), FIS, Ministry of Health, Madrid; and by project no. 2012/042 of the PROMETEO Program, Generalitat Valenciana, Valencia, Spain.

The study was conducted taking advantage of a 6-month predoctorate fellowship stay of the first author (Lic. K. Afshan) in the Department of Parasitology of the University of Valencia, Spain, funded by the International Research Support Initiative Programme (IRSIP) of the Higher Education Commission (HEC) of Pakistan and Indigenous HEC Fellowship programme, Pakistan. Lic. C.A. Fortes-Lima received a predoctorate fellowship of the Programa de Ayudas Predoctorales de Formación de Personal Investigador, Spanish Ministry of Education and Science, Madrid.

\section{References}

Afshan K, Valero MA, Qayyum M, Peixoto RV, Magraner A, Mas-Coma S, 2013. Phenotypic description of Fasciola hepaticalFasciola gigantica intermediate forms infecting buffaloes from Central Punjab, Pakistan. J Helminthol 4, 1-10.

Ahmed S, Nawaz M, Gul R, Zakir M, Razzaq A, 2005. Diversity and prevalence of trematodes in livers of sheep and goat in Quetta, Pakistan. Pak J Zool 37, 205-210.

Armour J, 1975. The epidemiology and control of bovine fascioliasis. Vet Rec 96, 198-201.

Azam M, Siddiqi MM, Habi G, 2002. Prevalence of parasitic infection in buffalo calves in Khadagzai, District Dir. Pak Vet J 22, 87-90.

Bargues MD, Mas-Coma S, 2005. Reviewing lymnaeid vectors of fascioliasis by ribosomal DNA sequence analyses. J Helminthol 79, 257-267.

Basharat M, Hashmi D, 2010. Groundwater management and recharge potential as an alternate to mega surface storages. In: Communicating Water Quality Challenges and Opportunities, World Water-Day March 2010. SMA Zaidi (ed), Pakistan Engineering Congress, Lahore, 114-131 pp.

Bhutto B, Phullan MS, Rind R, Soomro AH, 2002. Prevalence of gastro-intestinal helminths in buffalo calves. OnLine J Biol Sci 2, 43-45.

Buriro SN, Chaudhry AH, 1981. Incidence of limnaeid snails and occurrence of trematode larvae (Fasciola sp.). J Anim Sci 3, 1-6.

Chaudhry AH, Niaz M, 1984. Liver fluke - a constant threat to livestock development. Pak Vet J 4, 42-43.

Chaudhry NI, Mohmood M, Ahmad S, 1984. A note on economic losses due to fascioliasis in cattle and sheep. Pak Vet J 4, 45-46.

Cruz RV, Harasawa H, Lal M, Wu S, Anokhin Y, Punsalmaa B, Honda Y, Jafari M, Li C, Huu Ninh N, 2007. Asia. In: Climate change 2007: impacts, adaptation and vulnerability. Contribution of working group II to the fourth assessment report of the Intergovernmental Panel on Climate Change. Parry ML, Canziani OF, Palutikof JP, van der Linden PJ, Hanson CE (eds). Cambridge, Cambridge University Press, 469-506 pp.

Delfiner P, 1976. Linear estimation of non-stationary spatial phenomena. In: Advanced geostatistics in the mining industry. Guarasio M, David M, Haijbegts C (eds). Reidel Dordrecht, Netherlands, 49-68 pp.

Dinnik JA, Dinnik NN, 1963. Effects of seasonal variations of temperature on development of Fasciola gigantica in the snail host in the Kenyan highlands. Bull Epiz Dis Afr 11, 197-207. Durrani MS, Chaudhry NI, Anwar AH, 1981. The incidence of gastro-intestinal parasitism in sheep and goats of Jhelum valley (Azad Kashmir). Pak Vet J 1, 164-165.

Espinoza JR, Maco V, Marcos L, Saez S, Neyra V, Terashima A, Samalvides F, Gotuzzo E, Chavarry E, Huaman C et al., 2007. Evaluation of Fas2-ELISA for the serological detection of Fasciola hepatica infection in humans. Am J Trop Med Hyg 76, 977-982.

FAO, 1994. Diseases of domestic animals caused by flukes: Epidemiology, diagnosis and control of Fasciola, paramphistome, Dicrocoelium, Eurytrema and schistosome infections of ruminants in developing countries. Food and Agriculture Organization, p. 49.

Farooq AB, Khan AH, 2004. Climate change perspective in Pakistan. In: Proceedings of the capacity building APN workshop on global change research, Islamabad, 39-46 pp.

Fuentes MV, Malone JB, Mas-Coma S, 2001. Validation of a mapping and predicting model for human fasciolosis transmission in Andean very high altitude endemic areas using remote sensing data. Acta Trop 79, 87-95.

Fuentes MV, Valero MA, Bargues MD, Esteban, JG, Angles R, Mas-Coma S, 1999. Analysis of climatic data and forecast 
indices for human fascioliasis at very high altitude. Ann Trop Med Parasitol 93, 835-850.

Gadahi JA, Arshed MJ, Ali Q, Javaid SB, Shah SI, 2009. Prevalence of gastrointestinal parasites of sheep and goat in and around Rawalpindi and Islamabad, Pakistan. Vet World 2, 51-53.

Girones N, Valero MA, Garcia-Bodelon MA, Chico-Calero MI, Punzon C, Fresno M, Mas-Coma S, 2007. Immune supression in advanced chronic fascioliasis: an experimental study in a rat model. J Inf Dis 195, 1504-1512.

Hayat CS, Iqbal Z, Hayat B, Khan MN, 1986. Studies on the seasonal prevalence of fascioliasis and lungworm disease in sheep at Faisalabad. Pak Vet J 6, 131-134.

Hussain MS, Lee S, 2009. A classification of rainfall regions in Pakistan. J Kor Geogr Soc 44, 605-623.

IPCC, 2001. Climate change 2001: the scientific basis. In: Contribution of working group I to the third assessment report of the Intergovernmental Panel on Climate Change, Houghton JT, Ding Y, Griggs DJ, Noguer M, van der Linden PJ, Dai X, Maskell K, Johnson CA (eds). Cambridge University Press, Cambridge, 881 pp.

Iqbal MU, Sajid MS, Husain A, Khan MK, 2007. Prevalence of helminth infections in dairy animals of Nestle milk collection areas of Punjab, Pakistan. Ital J Anim Sci 6, 935-938.

Iqbal Z, Hayat CS, Hayat B, 1986. Natural infection of helminths in livers and lungs of sheep and goats. Pak J Agric Sci 23, 136-140.

Kahn SU, Hasan MU, Kahn FK, Bari A, 2010. Climate classification of Pakistan. In: 4th International Scientific Conference BALWOIS 2010 on water observation and information system for decission support, institut balkanique de l'eau et de l'environnement, Ohrid, Republic of Macedonia (25-29 May 2010), pp. 1-47.

Kakar MN, Kakarsulemankhel JK, 2008. Prevalence of endo (Trematodes) and ecto-parasites in cows and buffaloes of Quetta, Pakistan. Pak Vet J 28, 34-36.

Kakar MN, Masood MI, Janbaz KH, Qadir MI, Masood I, Kakarsulemankhel JK, 2011. Prevalence of fascioliasis in cows and buffaloes in Quetta, Pakistan. Pharmacologyonline 2, 974-978.

Kendall SB, 1954. Fascioliasis in Pakistan. Ann Trop Med Parasitol 43, 307-313.

Khan MK, Sajid MS, Khan MN, Iqbal Z, Iqbal MU, 2009. Bovine fasciolosis: Prevalence, effects of treatment on productivity and cost benefit analysis in five districts of Punjab, Pakistan. Res Vet Sci 87, 70-75.

Khan MN, Sajid MS, Khan MK, Iqbal Z, Arshad M, Hussain A, 2011. Point prevalence of bovine fascioliasis and the influence of chemotherapy on the milk yield in a lactating bovine population from the district of Toba Tek Singh, Pakistan. J Helminthol 85, 334-338.

Khan MN, Sajid MS, Khan MK, Iqbal Z, Hussain A, 2010.
Gastrointestinal helminthiasis: prevalence and associated determinants in domestic ruminants of district Toba Tek Singh, Punjab, Pakistan. Parasitol Res 107, 787-794.

Lashari MH, Tasawar Z, 2011. Prevalence of some gastrointestinal parasites in sheep in southern Punjab, Pakistan. Pak Vet J 31, 295-298.

Malik SZ, Haq IU, Jabeen F, Chaudhary MA, 1995. Incidence of endoparasites of ovine and caprine species in Punjab. Pak Vet J 15, 49-50.

Malone JB, Gommes R, Hansen J, Yilma JM, Slingenberg J, Snijders F, Nachtergaele F, Ataman E, 1998. A geographic information system on the potential distribution and abundance of Fasciola hepatica and F. gigantica in East Africa based on Food and Agriculture Organization databases. Vet Parasitol 78, 87-101.

Maqbool A, Hashmi HA, Shafique M, Akhtar T, Ahmad M, Mahmood F, 2000. Epidemiology and chemotherapy of fascioliasis in goats. Indian J Anim Res 34, 33-36.

Maqbool A, Hayat CS, Akhtar T, Hashmi HA, 2002. Epidemiology of fascioliasis in buffaloes under different management conditions. Vet Arhiv 72, 221-228.

Maqbool A, Hayat CS, Tanveer A, Salahuddin M, Arfan A, 2003. Prevalence and ecology of Lymnaea snails in Punjab. Iran J Vet Res 8, 192-195.

Mas-Coma S, Bargues MD, 1997. Human liver flukes: a review. Res Rev Parasitol 57, 145-218.

Mas-Coma S, Valero MA, Bargues MD, 2008. Effects of climate change on animal and zoonotic helminthiases. In: Climate change: impact on the epidemiology and control of animal diseases. de La Rocque S, Hendrickx G, Morand S (eds). Scientific and Technical Review, World Organisation for Animal Health (OIE), Paris. Rev Sci Tech Off Int Epiz 27, 443-457.

Mas-Coma S, Valero MA, Bargues MD, 2009a. Fasciola, lymnaeids and human fascioliasis, with a global overview on disease transmission, epidemiology, evolutionary genetics, molecular epidemiology and control. Adv Parasitol 69, 41-146.

Mas-Coma S, Valero MA, Bargues MD, 2009b. Climate change effects on trematodiases, with emphasis on zoonotic fascioliasis and schistosomiasis. Vet Parasitol 163, 264-280.

Masud FS, Majid A, 1984. Incidence of fascioliasis in buffaloes and cattle of Multan division. Pak Vet J 4, 33-34.

Nawaz M, Nawaz Y, 1987a. Problem of fascioliasis in sheep and goats in the province of Baluchistan, Pakistan. Proc Pakistan Congr Zool 7, 84-85.

Nawaz M, Nawaz Y, 1987b. Helminth parasites of liver and respiratory tracts of sheep and goats in the province of Baluchistan, Pakistan. Proc Pakistan Congr Zool 7, 86-87.

Nizamani A, Rauf F, Khoso AH, 1998. Case study Pakistan. Population and water ressources. In: water and population dynamics: case studies and policy implications. De Sherbinin A, Dompke V (eds). American Association for the Advancement of Science (AAAS), Washington DC, iv + 322 pp. 
Ollerenshaw CB, 1971. The influence of climate on the life cycle of Fasciola bepatica in Britain with some observations on the relationship between climate and the incidence of fasciolasis in the Netherlands. In: Facts and reflections, symposium proceedings (3 June 1971), Parasitology Department of the Centraal Diergeneeskundig Institut, Lelystad, pp. 41-63.

Ollerenshaw CB, 1973. A comment on the epidemiology of Fasciola hepatica in Italy. Ann Fac Med Vet 20, 83-121.

Ollerenshaw CB, 1974. Forecasting liver-fluke disease. In: The effects of meteorological factors upon parasites, symposium of the British Society for Parasitology. Taylor AR, Muller R (eds). Blackwell Scientific Publications, Oxford, 33-52 pp.

Ollerenshaw CB, Rowlands WT, 1959. A method of forecasting the incidence of fascioliasis in Anglesey. Vet Rec 71, 591-598.

Ollerenshaw CB, Smith LP, 1969. Meteorological factors and forecast of helminthic diseases. Adv Parasitol 7, 283-232.

Periago MV, Valero MA, El Sayed M, Ashrafi K, El Wakeel A, Mohamed MY, Desquesnes M, Curtale F, Mas-Coma S, 2008. First phenotypic description of Fasciola hepaticalFasciola gigantica intermediate forms from the human endemic area of the Nile Delta, Egypt. Inf Gen Evol 8, 51-58.

Qureshi AW, 2008. Epidemiology, serodiagnosis and therapy of fasciolosis in humans and buffaloes in Punjab, Pakistan. PhD thesis, Department of Zoology, Univerrsity of the Punjab, Quaid-E-Azam, Lahore, 186 pp.

Qureshi AW, Tanveer A, 2009. Seroprevalence of fasciolosis in buffaloes and humans in some areas of Punjab, Pakistan. Pak J Sci 61, 91-96.

Qureshi AW, Tanveer A, Qureshi SW, Maqbool A, Gill TJ, Ali SA, 2005b. Epidemiology of human fasciolosis in rural areas of Lahore, Pakistan. Punjab Univ J Zool 20, 159-168.

Qureshi AW, Tanveer A, Qureshi SW, Maqbool A, Niaz S, 2005a. Epidemiological study of fasciolosis in buffaloes at different sites of Punjab province. Punjab Univ J Zool 20, 21-28.

Rasul G, Mahmood A, Sadiq A, Khan SI, 2012. Vulnerability of the Indus Delta to climate change in Pakistan. Pak J Meteorol 8, 89-107.

Raza MA, Iqbal Z, Jabbar A, Yaseen M, 2007. Point prevalence of gastrointestinal helminthiasis in ruminants in southern Punjab, Pakistan. J Helminthol 81, 323-328.

Razzaq A, Farique S, Jan S, Tareen S, 2002. Incidence of internal parasites in sheep and goats of Asghara valley in Ziarat district of Balochistan. Balochistan J Agric Sci 3, 43-50.

Rees G, Collins DN, 2004. An assessment of the potential impacts of deglaciation on the water ressources of the Himalaya. In: Snow and glacier aspects of water ressources management in the Himalayas, Centre for for Ecology and Hydrology, Oxfordshire, UK, Technical Reports, DFIP KAR Project No. R7890.

Shaikh AA, Bilquees FM, Khan MM, 2004. Bile duct hyperplasia and associated abnormalities in the buffaloes infected with Fasciola gigantica. Pak J Zool 36, 231-237.
Tanveer A, 1990. Studies on the life history of fresh water snails Lymnaea acuminata Lamarck, L. rufescens Gray and L. luteola Lamarck. Biologia 36, 25-32.

Tanveer A, Khan D, 1989. Seasonal variations in the environmental factors and snail populations in the four different habitats around Lahore. Punjab Univ J Zool 4, 31-69.

Tum S, Puotinen ML, Copeman DB, 2004. A geographic information system model for mapping risk of fasciolosis in cattle and buffaloes in Cambodia. Vet Parasitol 122, 141-149.

Tum S, Puotinen ML, Skerratt LF, Chan B, Sothoeun S, 2007. Validation of a geographic information system model for mapping the risk of fasciolosis in cattle and buffaloes in Cambodia. Vet Parasitol 143, 364-367.

Valero MA, Darce NA, Panova M, Mas-Coma S, 2001. Relationships between host species and morphometric patterns in Fasciola hepatica adults and eggs from the Northern Bolivian Altiplano hyperendemic region. Vet Parasitol 102, 85-100.

Valero MA, Girones N, Garcia-Bodelon MA, Periago MV, Chico-Calero I, Khoubbane M, Fresno M, Mas-Coma S, 2008. Anaemia in advanced chronic fasciolosis. Acta Trop 108, 35-43.

Valero MA, Marcos MD, Fons R, Mas-Coma S, 1998. Fasciola hepatica development in experimentally infected black rat, Rattus rattus. Parasitol Res 84, 188-194.

Valero MA, Mas-Coma S, 2000. Comparative infectivity of Fasciola hepatica metacercariae from isolates of the main and secondary reservoir animal host species in the Bolivian Altiplano high human endemic region. Folia Parasitol 47, 1722.

Valero MA, Navarro M, Garcia-Bodelon MA, Marcilla A, Morales M, Garcia JE, Hernandez JL, Mas-Coma S, 2006. High risk of bacterobilia in advanced experimental chronic fasciolosis. Acta Trop 100, 17-23.

Valero MA, Panova M, Comes AM, Fons R, Mas-Coma S, 2002. Patterns in size and shedding of Fasciola hepatica eggs by naturally and experimentally infected murid rodents. J Parasitol 88, 308-313.

Valero MA, Panova M, Mas-Coma S, 2005. Phenotypic analysis of adults and eggs of Fasciola hepatica by computer image analysis system. J Helminthol 79, 217-225.

Valero MA, Perez-Crespo I, Periago MV, Khoubbane M, MasComa S, 2009. Fluke egg characteristics for the diagnosis of human and animal fascioliasis by Fasciola hepatica and F. gigantica. Acta Trop 111, 150-159.

Valero MA, Periago MV, Perez-Crespo I, Angles R, Villegas F, Aguirre C, Strauss W, Espinoza JR, Herrera P, Terashima A et al., 2012a. Field evaluation of a coproantigen detection test for fascioliasis diagnosis and surveillance in human hyperendemic areas of Andean countries. PLoS Negl Trop Dis 6, e1812.

Valero MA, Periago MV, Perez-Crespo I, Rodriguez E, Perteguer MJ, Garate T, Gonzalez-Barbera EM, Mas-Coma S, 2012b. 
Assessing the validity of an ELISA test for the serological diagnosis of human fascioliasis in different epidemiological situations. Trop Med Int Health 17, 630-636.

Valero MA, Santana M, Morales M, Hernandez JL, Mas-Coma S, 2003. Risk of gallstone disease in advanced chronic phase of fascioliasis: an experimental study in a rat model. J Infect Dis $188,787-793$.

Yilma JM, Malone JB, 1998. A geographic information system forecast model for strategic control of fascioliasis in Ethiopia. Vet Parasitol 78, 103-127. 